\title{
Temperature monitoring indoor based on a 6LoWPAN network
}

\section{Monitoreo de la temperatura basado en una red 6LoWPAN en un espacio cerrado}

\author{
TAMARIZ-FLORES, Edna Iliana †', TORREALBA-MELÉNDEZ, Richard*”, BALBUENA-
} AGUILAR, Arturo’ and LÓPEZ-LÓPEZ, Mario"'

'Benemérita Universidad Autónoma de Puebla, Faculty of Computer Science, Mexico.

"Benemérita Universidad Autónoma de Puebla, Faculty of Electronic Sciences, Mexico.

ID $1^{\text {st }}$ Author: Edna Iliana, Tamariz-Flores / ORC ID: 0000-0002-0737-5177, CVU CONACYT ID: 172840

ID $1^{\text {er }}$ Coauthor: Richard, Torrealba-Meléndez / ORC ID: 0000-0001-5138-3281, CVU CONACYT ID: 172841

ID $2^{\text {nd }}$ Coauthor: Arturo, Balbuena-Aguilar

ID $3^{\text {rd }}$ Coauthor: Mario, López-López / ORC ID: 0000-0003-0267-6947, CVU CONACYT ID: 67677

DOI: $10.35429 /$ JSTA.2020.18.6.1.6

Received July 06, 2020; Accepted December 30, 2020

\begin{abstract}
Wireless sensor networks (WSN) are increasingly present in applications of daily life, such as health care, agriculture, and environmental monitoring. According to the definition of a smart city, it requires connectivity to exchange information based on various technologies such as the WSN for the Internet of Things. Therefore, a 6LoWPAN is a type of hybrid network connected to the Internet through devices with limited resources using IPv6. For that reason, a 6LoWPAN becomes key in the implementation of a WSN. Due to the situation derived from COVID-19, the sanitary measures established indoor will allow the development of applications such as the one presented in this work, which establishes temperature monitoring in a university laboratory. The focus of this project is based on analyze of data transmission in a 6LoWPAN implemented through the IEEE 802.15.4 standard. The devices used correspond to the Texas Instruments CC2650stk and a CC2531 packet sniffer. The monitored data is stored in a database for graphical presentation.
\end{abstract}

\section{Resumen}

Las redes inalámbricas de sensores, WSN (Wireless Sensor Network) se encuentran cada vez más presentes en aplicaciones de la vida diaria como el cuidado de la salud, agricultura y monitoreo ambiental. De acuerdo con la definición de una ciudad inteligente, requiere de la conectividad para intercambiar información basada en varias tecnologías como la WSN para el Internet de las Cosas. Por lo anterior, una red 6LoWPAN, es un tipo de red híbrida conectada a Internet por medio de dispositivos con recursos limitados utilizando IPv6. Es por ello, que una red 6LoWPAN llega a ser una clave en la implementación de una WSN. Debido a la situación derivada del COVID-19, las medidas sanitarias establecidas en espacios cerrados, permitirá el desarrollo de aplicaciones como la que presenta en este trabajo, el cual establece el monitoreo de la temperatura en un laboratorio universitario. El enfoque de este proyecto se basa en el análisis de la transmisión de datos en una red 6LoWPAN implementada a través del estándar IEEE 802.15.4. Los dispositivos utilizados corresponden al CC2650stk de Texas Instruments y un sniffer de paquetes CC2531. Los datos monitoreados son almacenados en una base de datos para su presentación en gráfica.

Monitoreo de temperatura, 6LoWPAN, 802.15.4

\footnotetext{
* Correspondence to Author (Email: richard.torrealba@correo.buap.mx)

$\dagger$ Researcher contributing as first author.
} 


\section{Introduction}

The speed with which the world comes to connect has risen day by day. Smart environments have gained popularity with the help of recent research, and these types of environments define the characteristics of a smart city [1]. Temperature is a commonly implemented parameter for monitoring in indoor environments [2]. The temperature in urban areas is relatively higher than in rural areas due to the lack of vegetation and open spaces in an urban environment [3]. In accordance with this, one of the preventive protection measures against COVID-19 is to regulate the temperature in the work laboratories, and thus avoid the concentration of people. Traditionally the temperature in an interior space is considered in 21 or 22 degrees. Therefore, there is a need in the monitoring and control of this parameter to prevent disease. In addition, in measurement and instrumentation laboratories it is required to maintain a stable temperature to be able to perform precision measurements.

Wireless sensor networks (WSN) [4, 5] are defined as the core of applications for the services offered by a smart city. In this type of networks, the sensors are limited devices, so the IETF proposes a low power network like 6LoWPAN to adapt IPv6 to the WSN environment [6].

There are works that address the idea of environmental monitoring to provide various applications to a smart city, such is the case of $\mathrm{J}$. Vcelák et al. [7], showing examples of smart structures for environmental monitoring applications. In this work it is emphasized that the human spends $90 \%$ of his life in interior spaces, so it is important to focus on the quality of an interior environment. T. Adiono et al. [2], designed, developed and demonstrated the performance of a portable sensor system for indoor environments. This system is capable of monitoring humidity and temperature through ZigBee technology and displaying measurements to the user on the smartphone. M. A. Pradhan et al. [8], developed a smart city system that detects different characteristics including climate monitoring in order to improve the way of life. B. Chang and X. Zhang [9] designed a temperature and humidity monitoring system based on fuzzy PID control technology, considering as core the CC2430 for the development of the nodes.
Finally, Y. Park et al. [6], propose a gateway system to support multiple monitoring system functions in a 6LoWPAN network. In this work they trace the data through the network protocol stack.

The works presented above undoubtedly show an innovative technology applied to environmental monitoring. However, they do not present the way in which the information is transmitted through the wireless network that they use to send the data. That is why, in the present work, the way to analyze a frame through the wireless medium and to be able to detect transmission failures is highlighted. In addition to understanding the structure of the frame, you can observe the times and extract parameters such as the received signal strength indicator RSSI (Received Signal Strength Indicator), which allows you to measure the power level of the received signals. Therefore, this work will provide the analysis of data transmission in a 6LoWPAN network implemented by CC2650stk devices for environmental monitoring, considering a multipoint-to-point network. In addition, the scope and limitations of the modules for the transmission of data in real time are defined. The information collected from this low-power network will be stored in a server database configured in ContikiOS on a laptop.

\section{LoWPAN network architecture}

The demand for a larger IP address space has focused on the use of the IPv6 network protocol with 128 bits, allowing an approximate $3.4 \times 10^{\wedge}$ 38 addresses available [10]. The IPv6 network through the Low Power Wireless Personal Area Network (6LoWPAN), standardized by the IETF, is based on IPv6 packets over the IEEE 802.15.4 standard in the PHY and MAC layers [11], as shown in Figure 1. This type of network consists of low-power devices equipped with sensors for applications in smart cities that require wireless connectivity with very low transmission rates [11]. This demand for new applications in sensor networks characterized by low power, low cost, distributed and selforganized, make the connection directly to the Internet through the IPv6 protocol. 


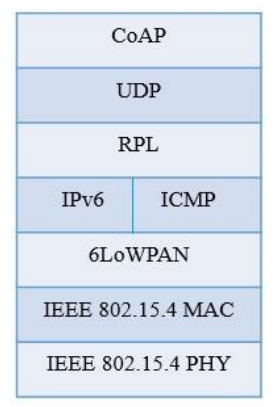

Figure 1 6LoWPAN protocol stack

In the 6LoWPAN model, the CSMA standard is used in the MAC layer and, in order to achieve energy saving, the Radio Duty Cycle Layer, RDC [10] is specified. The transport layer does not provide TCP connection, instead it uses UDP as the transport medium. The adaptation layer in the 6LoWPAN network receives this name because the IPv6 packets are adapted to the frame of the IEEE 802.15.4 standard through encapsulation and header compression mechanisms [10]. The RPL distance vector protocol [12] is considered the de facto routing protocol for the IoT. RPL creates a topology in the form of a destination-oriented acyclic graph (DODAG). The topology is created and maintained by ICMPv6-based control packets published by each node: DIO (DODAG information objects), DAO (Destination Advertisement Object) and DIS (DODAG Information Solicitation) [13].

\section{Network hardware and software}

CC2650stk SimpleLinkTM or IoT SensorTag has a CC2650 ultra low power wireless MCU that provides multiple $2.4 \mathrm{GHz}$ SimpleLink standards; Bluetooth Low Energy (BLE), as well as ZigBee and 6LoWPAN. This module developed by Texas Instruments Inc. is used in low-power sensor network applications, its tasks being the measurement of physical parameters, processing and analysis of readings, and wireless communication. This device has integrated sensors, the antenna and the microcontroller [14, 15]. For the development of this work, the HDC1000 temperature sensor was considered. The HDC1000 sensor is a factory-calibrated digital humidity sensor with an integrated temperature sensor that provides accurate measurements at very low power. In the case of temperature, it works within the range of $-40{ }^{\circ} \mathrm{C}$ to $125^{\circ} \mathrm{C}[16]$.
The CC2531 USB dongle in the CC2531EMK kit is programmed with the packet sniffer firmware and can be used for packet detection immediately [16]. For this work, the Wireshark version 3.0.5 network protocol analyzer was used to visualize the packets exchanged during communication between the motes of this project.

\section{Methodology for the design of the 6LoWPAN network}

This paper presents a 6LoWPAN network based on CC2650stk SimpleLinkTM transceiver devices with end-to-end IPv6 connectivity at the sensor nodes. Figure 2 shows the sensor node, which was configured through ContikiOS. This open operating system supports the routing protocol for low-power networks RPL (Routing Protocol for Low-Power and Lossy Networks) and 6LoWPAN.

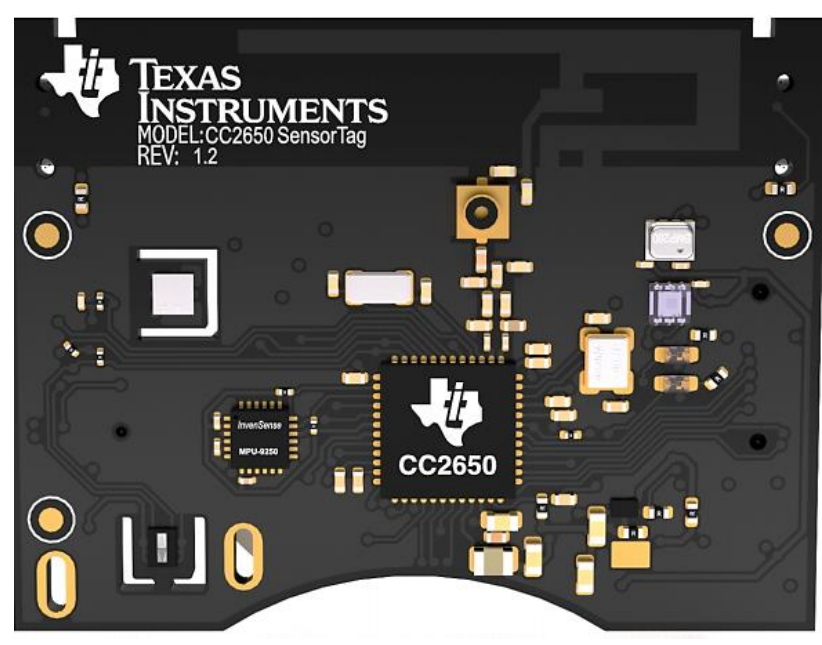

Figure 2 Transceptor CC2650stk SimpleLinkTM Source: Multi-Standard CC2650 SensorTag Design Guide. Instrumentos Texas. 2015

To perform the data transmission analysis, the network was implemented with three devices configured as end nodes, which carried out the temperature sensing. In addition, one more device was considered, configured as the network server to receive the temperature data. The list of nodes with their respective Linklocal addresses is shown in Table 1.

\begin{tabular}{|r|l|}
\hline \multicolumn{1}{l}{ Node ID } & \multicolumn{1}{c|}{ Link-Local Address } \\
\hline \multicolumn{1}{|c|}{ Server } & fe $80:: 212: 4 \mathrm{~b} 00: 129 \mathrm{a}: \mathrm{aa} 80$ \\
\hline 1 & fe80::212:4b00:1205:d71 \\
\hline 2 & fe $80:: 212: 4 \mathrm{~b} 00: 1204: \mathrm{fe} 77$ \\
\hline 3 & fe80::212:4b00:1204:fef6 \\
\hline
\end{tabular}

Table 1 Assignment of IDs and addresses on nodes 
Link-local addresses establish communication with other devices that belong to the same local link. They are limited to a single link so they cannot be routed beyond this link. Every interface has it. The range of these addresses is FE80:: / 10 to FEBF :: / 10.

Figure 3 shows the distribution of the nodes in the implemented network to be able to bring the information obtained to the end user.

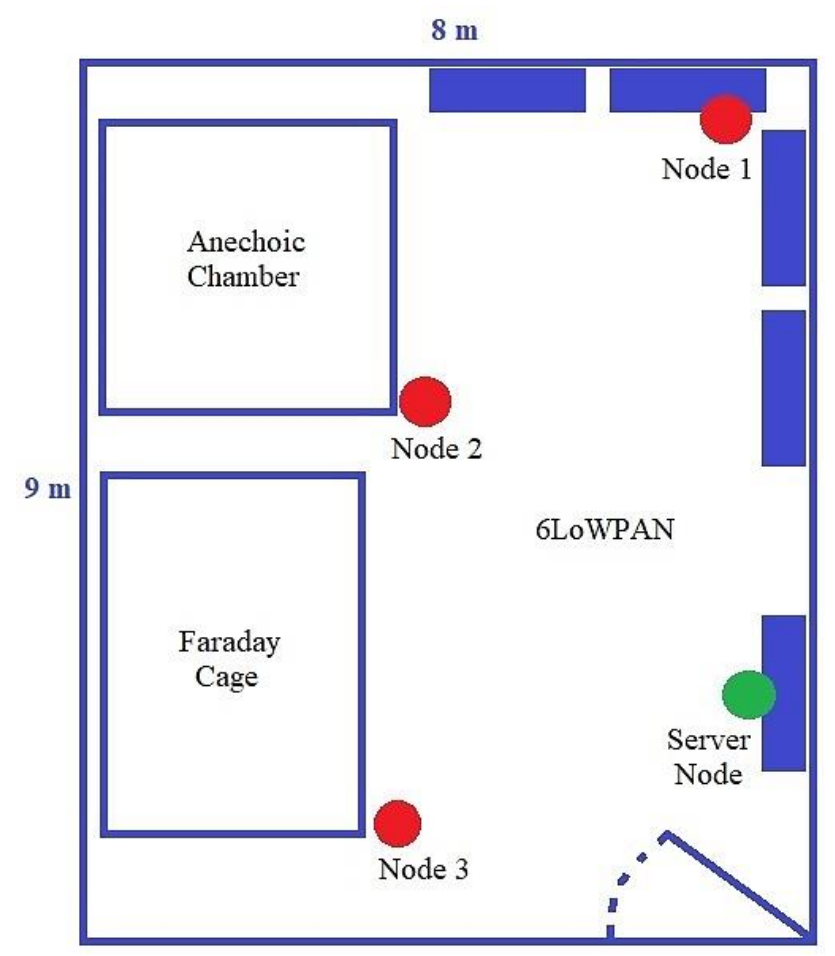

Figure 3 Node distribution for temperature monitoring in a closed space

\section{Results and analysis of system tests}

The implemented network was based on a multipoint-to-point communication and the tests were carried out in the Laboratory for Characterization of Microwave-Based Systems FCE-BUAP, this laboratory has a dimension of $8 \times 9 \mathrm{~m}$, where the nodes were placed as shown in Figure 3 Each one of the end nodes collects the data and internally transmits it to the wireless communication module. Subsequently, the data is transmitted to the server node through the 2.4 $\mathrm{GHz}$ antenna. Finally, the server node connected to the PC with ContikiOS, transmits the data through the USB serial port. Figure 4 shows the flow chart for the communication of this work.

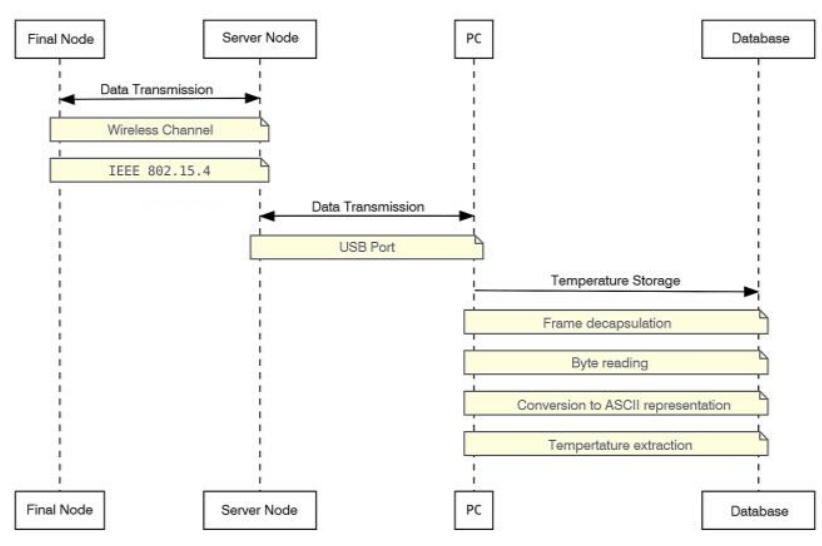

Figure 4 Flow diagram for processing the plot in ContikiOS

The end node will activate the radio periodically to sense the medium. This duty cycle was programmed with an active time of 15 $\mathrm{s}$ and a waiting time of $20 \mathrm{~s}$, in order that the data received at the server could be processed properly.

The server process establishes the node as the root of the topology, therefore, it sends the RPL control messages. Furthermore, this process creates the UDP connection to receive the data sensed by the end nodes. Figure 5 represents the above, where node 3 sends ICMPv6 control messages via a multicast address FF02 :: 1a. In this case, the DODAG Information Solicitation indicates that node 3 requests to join the network [17].

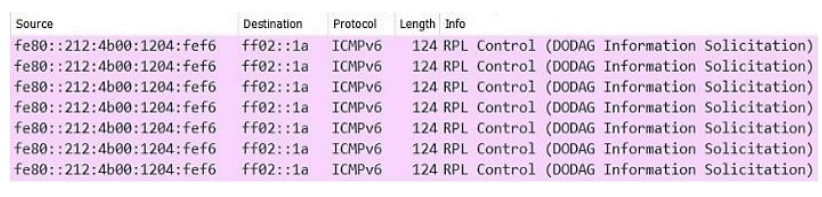

Figure 5 ICMPv6-based control packages published by node 3 in Wireshark

Because the temperature data collected by each end node is only sent to the serving node, the traffic is unicast. In this way, a confirmation message defined as ACK is handled to verify that the information arrived correctly at the server. This is shown in Figure 6. The figure shows the modified capture in Wireshark to indicate that node 3 sends the sensed temperature of $26.89^{\circ} \mathrm{C}$ to the server and, the latter confirms it with an ACK, all through the standard IEEE 802.15.4. 


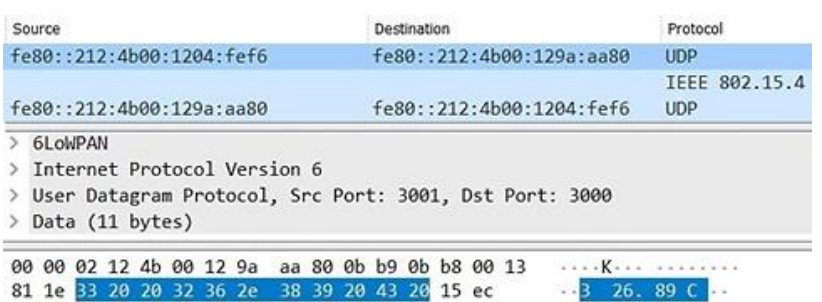

Figure 6 Obtaining Temperature Data in Wireshark

An important characteristic in the development of this project is that the information was evaluated in real time. Figure 7 shows the obtaining of the data in the server configured in ContikiOS. Each one of the nodes identified by their ID reports the temperature that each one detects. In this case, the temperature was modified manually by applying heat sources to show different variations.

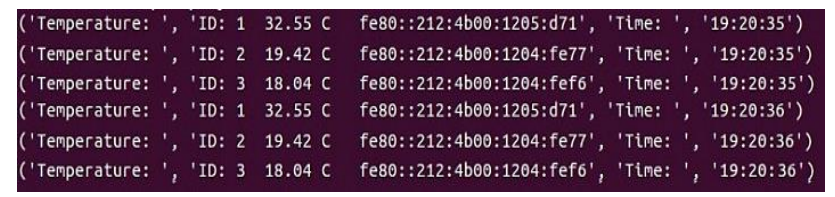

Figure 7 Obtaining temperature data in ContikiOS

The tests were carried out in a closed indoor environment where there was presence of other devices working in the same $2.4 \mathrm{GHz}$ band as a modem in IEEE 802.11n which caused the packets to be delayed. A determining factor in the data reception process was the work cycle, since the motes were not synchronized and each one carried out its period of inactivity, which caused that at that time there was no report on this. For the development of this work, the analysis of the frame received in the server node was fundamental, because with the decapsulation of each frame received, the temperature data was obtained. In this way the data were arranged in a database in the corresponding column for later analysis. Finally, Figure 8 shows the graph corresponding to the monitoring of the changing temperature of the three nodes at different points of time for a better user visualization.

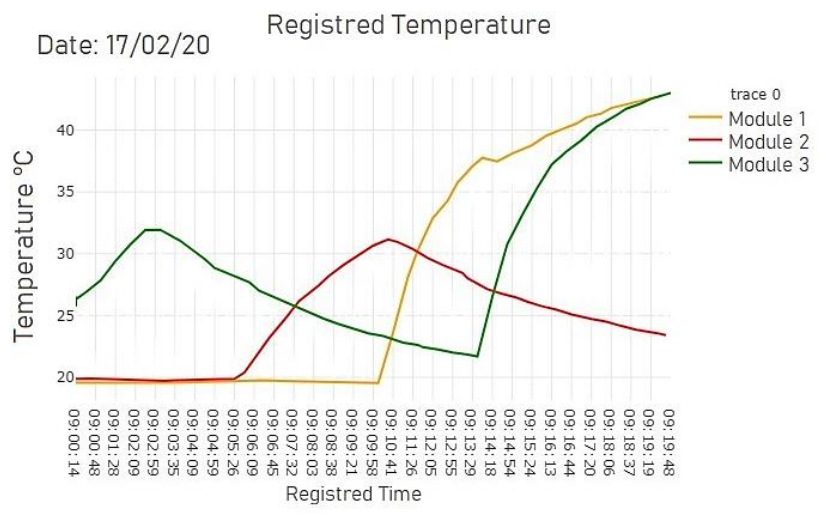

Figure $8 \mathrm{Graph}$ of temperature measurement with motes CC2650stk

\section{Conclusions}

In this work, a prototype was presented for monitoring the temperature inside a closed space based on a 6LoWPAN network. The development of this work served to analyze the transmission of information in this type of wireless networks. In addition, the use of lowpower devices is highlighted for the use of applications in smart cities, which when configured were applicable only for projects that do not require a large use of resources for real time, for this, dedicated servers can be used storage.

The application of this type of system will allow services to be even more beneficial in a smart city, both in the field of health and in the use of a low-power infrastructure.

\section{References}

[1] Kirimtat, A., et al. (2020). Future Trends and Current State of Smart City Concepts: A Survey. IEEE Access, 8, 86448-86467. https://doi.org/10.1109/ACCESS.2020.29 92441

[2] Adiono, T., et al. (2018). A portable node of humidity and temperature sensor for indoor environment monitoring. $3 r d$ International Conference on Intelligent Green Building and Smart Grid (IGBSG), Yi-Lan, pp. 1-5, doi: 10.1109/IGBSG.2018.8393575.

[3] Rashid, B., Rehmani, M. H. (2016). Applications of wireless sensor networks for urban areas: A survey. Journal of Network and Computer Applications, 60, pp.

https://doi.org/10.1016/j.jnca.2015.09.008 
[4] Amondaray, L. R., Fuentes, F. J. A., \& Calderón, C. A. (2020). Redes de Sensores Inalámbricos Definidas por Software. Revista Ingeniería Electrónica, Automática y Comunicaciones ISSN: 1815-5928, 41(2), 39-50.

[5] Romero Amondaray, L., Artigas Fuentes, F. J., \& Calderón, C. A. (2020). Redes de Sensores Inalámbricos Definidas por Software: revisión del estado del arte. Ingeniería Electrónica, Automática y Comunicaciones, 41(2), 39-50.

[6] Park, Y., et al. (2012). A network monitoring system in 6LoWPAN networks. Fourth International Conference on Communications and Electronics (ICCE), Hue, pp. 69-73, doi: 10.1109/CCE.2012.6315873.

[7] Včelák, J., et al. (2017). Smart building monitoring from structure to indoor environment. Smart City Symposium Prague (SCSP), Prague, pp. 1-5, doi: 10.1109/SCSP.2017.7973859.

[8] Pradhan, M. A. et al. (2017). IoT for smart city: Improvising smart environment. International Conference on Energy, Communication, Data Analytics and Soft Computing (ICECDS), Chennai, pp. 20032006, doi: 10.1109/ICECDS.2017.8389800.

[9] Chang, B., and Zhang, X. (2011). Design of indoor temperature and humidity monitoring system based on CC2430 and fuzzy-PID. Proceedings of 2011 Cross Strait Quad-Regional Radio Science and Wireless Technology Conference, Harbin, pp. 980-984, doi: 10.1109/CSQRWC.2011.6037121.

[10] Incipini, L., et al. (2019). Performance Evaluation of a Full IPv6-based Internet of Things Wireless Sensor Network. IEEE 23rd International Symposium on Consumer Technologies (ISCT), Ancona, Italy, pp. 333-338, doi: 10.1109/ISCE.2019.8900978.
[11] La, V. H., et al. (2016). A novel monitoring solution for 6LoWPAN-based Wireless Sensor Networks. 22nd Asia-Pacific Conference on Communications (APCC), Yogyakarta, pp. 230-237, doi: 10.1109/APCC.2016.7581493.

[12] Iova, O., et al. (2016). RPL: The Routing Standard for the Internet of Things... Or Is It?. IEEE Communications Magazine, 54(12), pp. 16-22.

[13] Xie, H., et al. (2014). Performance evaluation of RPL routing protocol in 6lowpan. IEEE 5th International Conference on Software Engineering and Service Science, Beijing, pp. 625-628, doi: 10.1109/ICSESS.2014.6933646.

[14] Multi-Standard CC2650 SensorTag Design Guide. Texas Instruments. 2015.

[15] CC2650 SimpleLink ${ }^{\mathrm{TM}}$ Multistandard Wireless MCU. Texas Instruments. 2015

[16] SmartRF ${ }^{\mathrm{TM}}$ packet Sniffer User's Manual. Texas Instruments. 2015.

[17] Quynh, T. N., et al. (2015). Multipath RPL protocols for greenhouse environment monitoring system based on Internet of Things, 12th International Conference on Electrical Engineering/Electronics, Computer, Telecommunications and Information Technology (ECTI-CON), Hua Hin, pp. 1-6, doi: 10.1109/ECTICon.2015.7207135. 